\title{
ANT BITE: A RARE CAUSE OF ANAPHYLAXIS IN PREGNANCY
}

Saif Zil Kibriya ${ }^{1}$, Nazneen Fatima², Sadaf Rakhshan ${ }^{3}$, Shireen Rokadia ${ }^{4}$

\section{HOW TO CITE THIS ARTICLE:}

Saif Zil Kibriya, Nazneen Fatima, Sadaf Rakhshan, Shireen Rokadia."Ant Bite: A Rare Cause of Anaphylaxis in Pregnancy". Journal of Evolution of Medical and Dental Sciences 2015; Vol. 4, Issue 01, January 01;

Page: 123-126, DOI: 10.14260/jemds/2015/19

ABSTRACT: Anaphylaxis during pregnancy can be catastrophic for both mother and her fetus. Ant bites are a rare cause of anaphylaxis in pregnant females. The manifestations of anaphylaxis in pregnant females have unusual features making diagnosis challenging. The pathophysiology could be explained by low levels of blood histamines in second and third trimester. Rapid identification and prompt treatment is a prerequisite for survival of both mother and her fetus.

KEYWORDS: Anaphylaxis, pregnancy, ant bite, histamine levels in pregnancy.

INTRODUCTION: Anaphylaxis is a serious life threatening, generalized or systemic hypersensitivity reaction, rapid in onset and can be fatal. ${ }^{1}$

The prevalence of anaphylaxis is estimated to be over $2 \% .^{2}$ Antbites are a rare cause of anaphylaxis. ${ }^{3}$ Very few reports of anaphylaxis by ant bites have been reported from Saudi Arabia, ${ }^{4}$ Europe, ${ }^{5}$ and Canada. ${ }^{5}$ Reports of anaphylaxis in pregnant females by ant bites has not been reported till date. We believe this is an exceptional case.

CASE REPORT: A 27 year old, G2P1L1, with full term pregnancy was rushed to the medical emergency with complaints of giddiness followed by a fainting spell 15 minutes after being bitten by an ant. She developed shortness of breath and onlookers described her as going pale.

There was no history suggestive of cardiovascular disorders or pulmonary embolism. History of previous episode of atopy or any allergy to food or animal products was absent. History of any unusual drug or food intake was also negative. Patient was on iron and folic acid since three weeks. On examination vitals were SBP $80 \mathrm{~mm} \mathrm{Hg}$ / DBP 50Hg, pulse rate was 120/ minute, thready pulse with normal rhythm. Respiratory rate was 32/minute. General physical examination showed cold, clammy skin with cyanosis of mucous membranes and extremities.

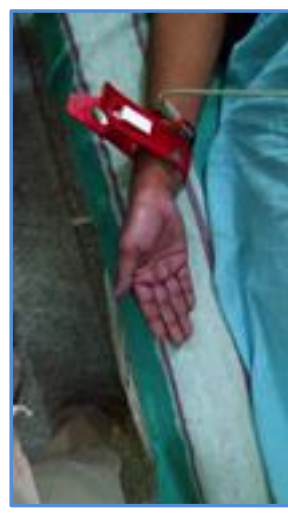

Fig. 1: Peripheral cyanosis (before treatment)

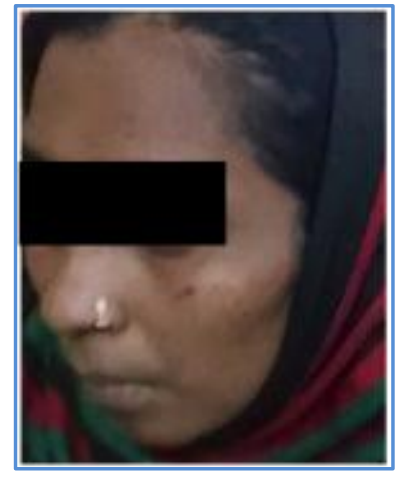

Fig. 2: Central cyanosis of mucous membranes (lips and tongue) 


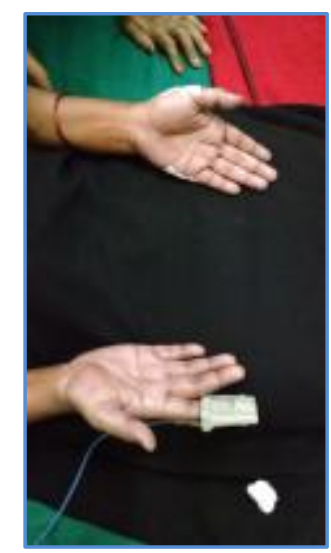

\section{Fig. 3: Cyanosis disappears after} adrenaline and shock management

Systemic examination was normal except bilateral rhonchi. Urticaria and angioedema was absent.

INVESTIGATIONS: Total count 15500, neutrophils - 77, L - 17, E - 06, ESR - 30. $1^{\text {st }} \mathrm{hr}$, serum sodium - 139, serum potassium - 3.9, serum chloride - 108 , serum creatinine -0.7 , blood urea -16 , random blood sugar $-84 \mathrm{mg} / \mathrm{dl}$.

ECG was normal except tachycardia. ECHO and D-Dimer test were found to be normal.

Patient was immediately resuscitated with 100\% oxygen, bag and mask ventilation, supported with IV normal saline and administered adrenaline. She recovered from the shock and delivered a normal baby 2 days from the date of admission in the labour room. The suspected insect was sent to the department of entomology and species was identified as Solenopsis geminate.

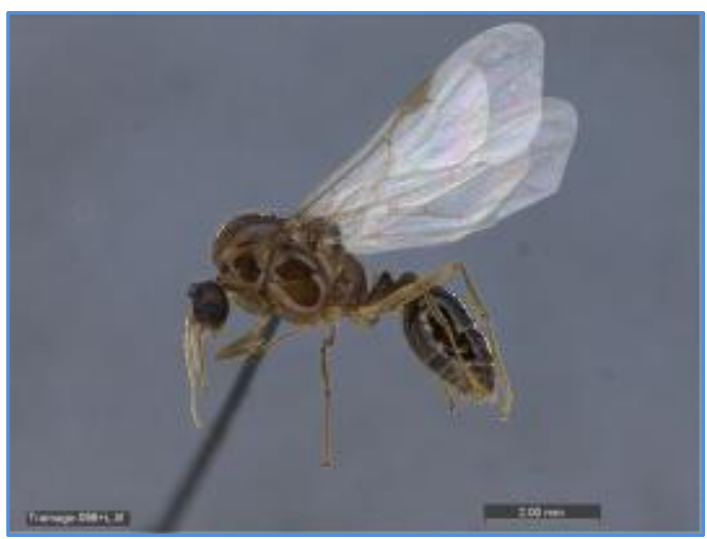

\section{Fig. 4: Solenopsis geminate.* courtesy picture *}

CONCLUSION: Ant bites can cause anaphylaxis in pregnant females, keen clinical observation, early diagnosis and prompt treatment can be the key for dual survival. 


\section{CASE REPORT}

\section{DISCUSSION: Diagnosis of anaphylaxis is Clinical:}

Anaphylaxis is highly likely where one of the following criteria is fulfilled;

1. Two or more occurring rapidly after exposure to a likely allergen (Minutes-few hours)

A. Involvement of skin, mucosal tissue (eg. Generalised urticaria, itching, swollen lips).

B. Respiratory compromise (eg. Dyspnoea, wheeze, broncospasm, stridor, reduced $\mathrm{pO}_{2}$ ).

C. Reduced blood pressure or symptoms suggestive (eg. Syncope, collapse).

D. Persistent GIT symptoms (eg. Crampy abdominal pain).

\section{Acute onset of illness (Minutes-several hours) with involvement of skin, mucosal tissue or both and atleast one of these;}

A. Respiratory compromise (eg. Dyspnoea, wheeze, broncospasm, stridor, reduced $\mathrm{pO}_{2}$ )

B. Reduced blood pressure or symptoms suggestive (eg. Syncope, collapse) ${ }^{6}$

Anaphylaxis in pregnancy can have unique features including intense itching in the vulval and vaginal areas, low back pain, uterine cramps, cardiovascular collapse, fetal distress and preterm labour. ${ }^{3}$

\section{Etiology of anaphylaxis in pregnancy Includes;}

a. During pregnancy: Foods, sting venom insects including fire fly, medications, biological agents, natural rubber latex.

b. During labour and delivery: Antibiotics, natural rubber latex, neuromuscular blockers, oxytocin, local anaesthetics, blood and its products. ${ }^{3}$

Insects of the order hymenoptera, members of the genus solenopsis namely Sinvicta, S. richteri and S. germinate have stinging apparatus at the tail end of their abdominal segments. ${ }^{7}$ Fire ant venom is $95 \%$ alkaloid with a small aqueous fraction that contains soluble protein. $99 \%$ of which is 2-6 disubstituted piperidines, which have haemolytic, antibacterial, insecticidal and cytotoxic properties. The protein in fire ants making up $0.1 \%$ of the venom induces Ig E response in person allergic to fire ant stings. ${ }^{8}$

In the present case on being bitten by an ant, the patient developed cardiovascular collapse within 15 minutes. A cardiac cause could not be found by ECG or ECHO. A normal D dimer test rules out the probability of pulmonary thromboembolism; thereby suggesting an anaphylactic or hypersensitivity response to ant venom. The presence of raised specific IgE confirms the above diagnosis.

The paucity of skin and mucosal signs including (Urticaria, wheals, angiodema) remains unexplained. The probable mechanism could be explained by low level of blood histamine found in pregnant females during second and third trimester. Reports by Laura, Verna et al. support this concept. ${ }^{9}$ This case report assumes significance because classical signs of anaphylaxis may be absent in pregnant females stung by ants making diagnosis difficult.

\section{REFERENCES:}

1. Johansson SGO, Bieber T, Dahl R, Friedmann PS, Lanier BQ, Lockey RF, et al. Revised nomenclature for allergy for global use: Report of the Nomenclature Review Committee of the World Allergy Organization, October 2003. J Allergy Clin Immunol. 2004; 113: 832-836. 
2. Lieberman P, Camargo CA, Jr, Bohlke K, Jick H, Miller RL, Sheikh A, et al. Epidemiology of anaphylaxis: findings of the American College of Allergy, Asthma and Immunology Epidemiology of Anaphylaxis Working Group. Ann Allergy Asthma Immunol. 2006; 97: 596-602

3. EstelleR. Simons, anaphylaxis during pregnancy. J allergy Clin Immunol. 2012; 130: 3 (p597606).

4. Al-Shahwan M, Al-Khenaizan S, Al-Khalifa M. Black (Samsum) ant induced anaphylaxis in Saudi Arabia. Saudi Med J. 2006; 27: 1761-3.

5. Fernandez-Melendez S, Miranda A, Garcia-Gonzalez JJ, Barber D, Lombardero M. Anaphylaxis caused by imported red fire ant sting in Malaga, Spain. J Investig Allergol Clin Immunol. 2007; 17: 48-9.

6. Estelle R. Simons, Ledit R. F. Ardusso, M. Beatrice Bilò et al, World Allergy Organization Guidelines for the Assessment and Management of Anaphylaxis J allergy Clin Immunol. 2001; 127: 593 (e1-220).

7. Freeman T M, hypersensitivity to hymenoptera stings. N Engl J Med. 2004; 351: 1978-84.

8. De Shaze RD, Butcher BT, Banks WA. Reactions to the stings of imported fire ant. N Engl J Med. 1990; 323: 462-6.

9. Maintz L, Schwarzer V, Bieber T et al. effects of histamine and diamine oxidase activity on pregnancy: a critical review; hum. reprod. Update (2008) 14 (5); 485-495.

\section{AUTHORS:}

1. Saif Zil Kibriya

2. Nazneen Fatima

3. Sadaf Rakhshan

4. Shireen Rokadia

\section{PARTICULARS OF CONTRIBUTORS:}

1. Senior Resident, Department of Medicine, ESIC Medical College, Gulbarga.

2. Assistant Professor, Department of OBG, Shadan Institute of Medical Sciences.

3. Consulting Gynaecologist, Department of OBG, ESIC Medical College, Gulbarga.
4. Assistant Professor, Department of Optholomogy, Saptagiri Institute of Medical Sciences, Bangalore.

\section{NAME ADDRESS EMAIL ID OF THE} CORRESPONDING AUTHOR:

Dr. Saif Zil Kibriya, C/o Laequr Baqtiyar, \# 5/993/277, Ring Road Extension, Makkah Colony, Gulbarga, Karnataka.

E-mail: saifkibriya@gmail.com

Date of Submission: 14/12/2014. Date of Peer Review: 15/12/2014. Date of Acceptance: 23/12/2014. Date of Publishing: 01/01/2015. 